\title{
Uso de extratos vegetais no controle de fungos fitopatogênicos
}

\author{
Kátia Regina Freitas Schwan-Estrada ${ }^{1}$ \\ José Renato Stangarlin ${ }^{2}$ \\ Maria EugÊNia da Silva CruZ
}

\section{INTRODUÇÃO}

Atualmente, em todos os lugares do mundo onde se pratica uma agricultura econômica, a intervenção para o controle de doenças de plantas é largamente realizada através de pesticidas (KIMATI et al., 1997). Sem dúvida, o uso racional desses produtos pode ter, em curto prazo, um efeito positivo para o produtor. No entanto, em longo prazo, além do surgimento de isolados dos fitopatógenos resistentes às substâncias químicas utilizadas, os resultados para a sociedade como um todo e para o meio ambiente podem se tornar negativos devido à poluição causada pelos resíduos. Nesse contexto, termos como "agricultura alternativa" ou "agricultura sustentável" obtêm expressão política (ZADOKS, 1992) e estimulam a busca por novas medidas de proteção das plantas contra as doenças.

Um dos enfoques da agricultura alternativa é o controle alternativo de doenças de plantas, o qual inclui o controle biológico e a indução de resistência em plantas (não são incluídos nesse conceito o controle químico clássico e o melhoramento genético (BETTIOL, 1991)).

O controle biológico pode ser definido como o controle de um microrganismo através da ação direta de um outro microrganismo antagônico, o qual pode atuar por meio de antibiose, parasitismo, competição, predação ou hipovirulência (COOK \& BAKER, 1983).

A indução de resistência (ou indução de proteção, imunidade adquirida, ou resistência sistêmica adquirida) envolve a ativação de mecanismos de defesa latentes, existentes nas plantas, em resposta ao tratamento com agentes bióticos ou abióticos (HAMMERSCHMIDT \& DANN, 1997). Esses mecanismos de resistência induzidos podem ser estruturais, como papila, lignificação e tilose, ou bioquímicos, como o acúmulo de fitoalexinas e de proteínas relacionadas à patogênese (como $\beta-1,3$ glucanase e quitinase degradadoras da parede celular de fungos) (PASCHOLATI \& LEITE, 1995). Essa ativação pode ser obtida pelo tratamento com agentes bióticos (como microrganismos viáveis ou inativados) (STANGARLIN \& PASCHOLATI,

${ }^{1}$ (Fundação Universidade Estadual de Maringá - Centro de Ciências Agrárias - Departamento de Agronomia - Av. Colombo, 5790 - 87020-900 - Maringá - PR schwan@wnet.com.br);

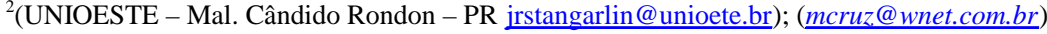


1994) ou abióticos, como ácido 2,6-dicloroisonicotínico (HIJWEGWN et al., 1996) e benzo (1, 2, 3)tiadiazol-7 carbotióico (Ciba, 1995). A proteção conferida pelo tratamento é capaz de proteger a planta contra infecções subseqüentes por diferentes patógenos (KUC, 1995) e mostra-se como uma estratégia potencial para o controle fitossanitário (LYON et al., 1995). A indústria de defensivos já tem desenvolvido moléculas, não pesticidas, capazes de protegerem uma cultura contra os patógenos causadores de doenças apenas pela indução dos mecanismos de defesa da planta (ZADOKS, 1997). Moléculas ou agentes de origem biótica ou abiótica, capazes de ativar ou induzir qualquer resposta de defesa nas plantas, são chamadas de elicitores (SMITH, 1996). A variada natureza química dos elicitores, tais como oligossacarídeos, glicoproteínas, oligopeptídeos e ácidos graxos demonstra que não há uma característica estrutural única que determine a atividade elicitora.

As fitoalexinas são metabólitos secundários, antimicrobianos, de baixo peso molecular e produzido pelas plantas em resposta a estresses físicos, químicos ou biológicos, sendo capazes de impedir ou reduzir a atividade de agentes patogênicos (PURKAYASTHA, 1995). De forma geral, o modo de ação das fitoalexinas sobre fungos inclui granulação citoplasmática, desorganização dos conteúdos celulares, ruptura da membrana plasmática e inibição de enzimas fúngicas. Esses efeitos refletem-se na inibição da germinação e elongação do tubo germinativo e redução ou inibição do crescimento micelial (LO et al., 1996). Mais de 300 fitoalexinas já foram caracterizadas entre diferentes classes de compostos químicos como cumarina, diterpeno e flavonóide, entre outras, tendo sido identificadas em mais de 20 famílias de vegetais superiores (SMITH, 1996). Em sorgo são conhecidas quatro fitoalexinas (flavonóides 3-deoxiantocianidinas): luteolinidina, 5metoxiluteolinidina, apigeninidina e éster do ácido cafeico de arabinisol 5- $O$ apigeninidina (NICHOLSON et al., 1987). No caso da soja, a fitoalexina gliceolina (pterocarpanóide) mostra-se importante na interação dessa leguminosa com fitopatógenos (BURDEN \& BAILEY, 1975). Mesocótilos estiolados de sorgo e cotilédones de soja mostram-se como excelentes ferramentas para estudos envolvendo a ação elicitora de moléculas de origem biótica e abiótica.

A exploração da atividade biológica de compostos secundários presentes no extrato bruto ou óleo essencial de plantas medicinais pode se constituir, ao lado da indução de resistência, em mais uma forma potencial de controle alternativo de doenças em plantas cultivadas. Algumas espécies estudadas sob este aspecto são: Baccharis trimera, Eucalyptus citriodora, Cymbopogon citratus, C. martinii, Ocimum gratissimum. No Brasil, somente $20 \%$ da população consome $63 \%$ dos medicamentos disponíveis, enquanto que o restante encontra nos medicamentos de origem natural, especialmente nas plantas medicinais, a única fonte de recurso terapêutico (DI STASI, 1996a). Até o momento, ainda não se conhece quase nada sobre a composição química 
de $99,6 \%$ das plantas de nossa flora, estimadas entre 40 mil a 55 mil espécies (MING, 1996). Além disso, uma grande quantidade de compostos secundários das plantas medicinais já isolados e com estrutura química determinada, ainda não foi estudados quanto suas atividades biológicas. Esses compostos pertencem a várias classes distintas de substâncias químicas, como alcalóides, terpenos, lignanas, flavonóides, cumarinas, benzenóides, quinonas, xantonas, lactonas e esteróides, entre outras (DI STASI, 1996b). Quando esses compostos são extraídos das plantas por processos específicos, como a destilação por arraste de vapor de água, originam líquidos de consistência semelhante ao óleo, voláteis, dotados de aroma forte, quase sempre agradável, insolúveis em água e solúveis em solventes orgânicos, denominados de óleos essenciais (SILVA et al., 1995). Compostos secundários de plantas medicinais estão distribuídos em um grande número de famílias botânicas, com muitos deles apresentando atividade antimicrobiana, como é o caso dos alcalóides, com origem biossintética a partir da via metabólica do ácido shiquímico (BENNETT \& WALLSGROVE, 1994).

Trabalhos desenvolvidos com extrato bruto ou óleo essencial, obtido a partir de plantas medicinais da flora nativa, têm indicado o potencial das mesmas no controle de fitopatógenos, tanto por sua ação fungitóxica direta, inibindo o crescimento micelial e a germinação de esporos, quanto pela indução de fitoalexinas, indicando a presença de composto(s) com característica de elicitor (es). O fracionamento dos metabólitos secundários dessas plantas, bem como a determinação da atividade biológica dessas moléculas, com respeito à atividade elicitora ou antimicrobiana, poderão contribuir para a aquisição de maiores conhecimentos que reforcem sua possível utilização como um método alternativo de controle de doença de plantas.

Tanto o extrato bruto quanto o óleo essencial de plantas medicinais (alecrim (Rosmarinus officinalis), manjerona (Origanum majorana), alfavaca (Ocimun basilicum), mentrasto (Ageratum conyzoides), babosa (Aloe vera), mil-folhas (Achillea millefolium), orégano (Origanum vulgare), cardo santo (Argemone mexicana), pitanga (Stenocalyx michelli), erva cidreira (Lippia alba), poejo (Mentha pulegium), hortelã pimenta (Mentha piperita), romã (Punica granatum), goiabeira vermelha (Psidium guayava var. pomifera), eucalipto lima (Eucalyptus citriodora), manjericão (Ocimum basilicum), arruda (Ruta graveolens) e carqueja (Baccharis trimera)) têm sido utilizados para estudos, in vitro, de inibição de crescimento micelial e esporulação de fungos fitopatogênicos (Rhizoctonia solani, Sclerotium rolfsii, Alternaria alternata, Phytophthora sp. e C . graminicola) e em bioensaios para a indução de fitoalexinas em sorgo (deoxiantocianidinas) e soja (gliceolina).

Bioensaios realizados por SCHWAN-ESTRADA et al (1997) para a síntese de deoxiantocianidinas em mesocótilos de sorgo, com diferentes plantas medicinais, mostraram que os extratos brutos de romã, erva cidreira, 
manjerona, babosa e orégano foram os mais efetivos, entre as plantas medicinais testadas, em induzir o acúmulo de um complexo de pigmentos (Tabela 1). A maior indução foi observada pelo tratamento com o patógeno $C$. graminicola, onde provavelmente se observa maior nível de reconhecimento e, portanto, maior ativação do metabolismo de defesa da planta. Os tratamentos com ultravioleta e $S$. cerevisiae mostraram baixa atividade elicitora, ao contrário do observado por WULFF \& PASCHOLATI (1998). Com relação à síntese de gliceolina em cotilédones de soja (Tabela 1), os extratos brutos de pitanga, cânfora, poejo, romã e cardo santo foram os mais efetivos, entre as plantas medicinais testadas, em induzir o acúmulo de gliceolina em cotilédones de soja. Os tratamentos com ultravioleta, $S$. cerevisiae e $C$. graminicola (não patógeno) também mostraram bons resultados.

Em ensaios para verificar a inibição de germinação de conídios de $C$. graminicola, BERNARDO et al (1998) verificaram que houve $100 \%$ de inibição na germinação em presença dos óleos essenciais de Ocimum basilicum, Baccharis trimera e Ruta graveolens. No tratamento controle a porcentagem de germinação foi de $92 \%$. Quando o extrato bruto aquoso de E. citriodora (Tabela 2) foi utilizado, ocorreu um estímulo à germinação dos esporos, embora tenha reduzido entre 14 e $34 \%$ a formação de apressórios em concentrações do extrato acima de 10\% (BONALDO et. al 1998). O apressório é uma estrutura necessária para penetração do patógeno no hospedeiro, de tal forma que a sua ausência implica em redução da porcentagem de infecção. Já para o crescimento micelial, houve $100 \%$ de inibição do crescimento micelial dos fungos testados em todas as alíquotas do óleo de manjericão (O. basilicum). Em óleo de carqueja (B. trimera), houve crescimento de todos os fungos até a alíquota de $100 \mu \mathrm{l}$ e inibição de $100 \%$ para as demais alíquotas $(500$ e $1000 \mu \mathrm{l})$. Em óleo de arruda ( $R$. graveolens), apenas A. alternata apresentou crescimento micelial até a alíquota de $40 \mu \mathrm{l}$ (inibição de $74 \%$ ), havendo inibição de $100 \%$ no crescimento nas demais alíquotas (Tabela 3). Quando em presença do extrato bruto, $R$. graveolens e $O$. basilicum inibiram totalmente o crescimento micelial de $S$. rolfsii em concentrações acima de $10 \%$. O extrato bruto de $B$. trimera apenas inibiu parcialmente o crescimento micelial dos fungos fitopatogênicos testados. Para Dydimella bryoniae, tanto o extrato bruto quanto os óleos essenciais de E. citriodora, Ageratum conyzoides e Cymbopogon citratus, inibiram completamente o crescimento micelial e a germinação dos conídios (FIORI et al., 2000).

Outros trabalhos desenvolvidos com plantas medicinais detectaram a presença de compostos fungitóxicos através de cromatografia de camada delgada. STANGARLIN et al (1997) verificaram a presença de frações nas quais houve inibição do desenvolvimento de $C$. graminicola. Observou-se a presença de duas frações fungitóxicas bem definida nos extratos de erva cidreira, e uma nos de cânfora e alfavaca. Uma pequena banda de inibição foi verificada nos extratos de orégano, mentrasto e alecrim. Os extratos de 
manjerona, mil-folhas, hortelã pimenta, cardo santo, romã, poejo, pitanga, babosa e goiabeira vermelha não apresentaram frações fungitóxicas.

\section{CONSIDERAÇÕES FINAIS}

As pesquisas realizadas in vitro indicam o potencial das plantas medicinais estudadas no controle de fungos fitopatogênicos e na indução de alguns mecanismos de defesa das plantas. No momento, as pesquisas estão sendo direcionadas para trabalhos in vivo utilizando-se patossistemas em feijoeiro, soja, pepino, trigo e sementes de cereais, com o objetivo de verificar a ocorrência de indução de resistência através do monitoramento da expressão dos sintomas da doença, bem como, de outros mecanismos de defesa da planta hospedeira, como a formação de papilas ou a síntese de proteínas relacionadas à patogênese. O fracionamento cromatográfico e a caracterização de frações elicitoras, dosagem e intervalo de aplicação que sejam mais eficientes e que não provoquem fitotoxidez fazem parte desta etapa. O objetivo final é obter, através do óleo essencial ou, principalmente do extrato bruto, uma tecnologia que possa ser repassada para pequenos produtores rurais, ou aqueles interessados no "cultivo orgânico", onde formas alternativas de controle de doenças são necessárias. Por outro lado, além desses benefícios no controle fitossanitário, o produtor rural teria a sua disposição um novo produto para comercializar, que são as próprias plantas medicinais.

\section{BIBLIOGRAFIA CITADA}

AYERS,A.R.; EBEL,J.; FINELLI,F.; BERGER,N.; ALBERSHEIM,P. Hostpathogen interactions. IX. Quantitative assays of elicitor activity and characterization of the elicitor present in the extracellular medium of cultures of Phytophthora megasperma var. sojae. Plant Physiology, v.57, p.751-759, 1976.

BENNETT,R.; WALLSGROVE,R.M. Secondary metabolites in plant defence mechanisms. New Phytologist, v.127, p.617-633, 1994.

BETTIOL,W. (Ed.). Controle Biológico de Doenças de Plantas. Jaguariúna: EMBRAPA-CNPDA, 1991. 388p. (EMBRAPA-CNPDA. Documentos, $15)$.

BERNARDO, R.; SCHWAN-ESTRADA， K.R.F; STANGARLIN， J.R.; CRUZ, M.E.S.; PASCHOLATI, S.F. Fungitoxicidade de alguns óleos essenciais contra fungos fitopatogênicos. Fitopatologia Brasileira , v.23 (Suplem.), p. 227.

BONALDO, S.M.; SCHWAN-ESTRADA, K.R.F.; J.R.; CRUZ, M.E.S.; PASCHOLATI, S.F. Inibição do crescimento micelial de fungos 
fitopatogênicos e indução de fitoalexinas por Eucalyptus citriodora.

Fitopatologia Brasileira , v.23 (Suplem.), p. 229.

BURDEN,R.J.; BAILEY,J.A. Structure of the phytoalexin from soybean.

Phytochemistry, v.14, p.1389-1390, 1975.

CIBA. CGA 245704. A plant activator for disease protection. Basel, CIBA

Technical Data Sheet, 9p. 1995.

COOK,R.J.; BAKER,K.F. The Nature and Practice of Biological Control of

Plant Pathogens. St. Paul: APS Press, 1983. 539p.

DI STASI,L.C. Plantas Medicinais: Arte e Ciência - Um Guia de Estudos

Multidisciplinar. São Paulo: Ed. Universidade Paulista. 1996a. 215p.

DI STASI,L.C. Química de produtos naturais: principais constituintes ativos.

In: DI STASI,L.C. (Ed.). Plantas Medicinais: Arte e Ciência - Um

Guia de Estudos Multidisciplinar. São Paulo: Ed. Universidade Paulista. 1996b. p.109-127.

FIORI, A.C.F.; SCHWAN-ESTRADA, K.R.F.; STANGARLIN, J.R.; VIDA, J.B.; SCAPIM, C.A.; CRUZ, M.E.S.; PASCHOLATI, S.F. Antifungal activity of leaf extracts and essential oilsof some medicinal plants against Dydimella bryoniae. Journal of Phytopathology, v.148, n.7/8, p. 483488, 2000

HAMMERSCHMIDT,D.; DANN,E.K. Induced resistance to disease. In: RECHCIGL,N.A.; RECHCIGL,J.E. (Ed.). Environmentally Safe Approaches to Crop Disease Control. Boca Raton: CRC - Lewis Publishers, 1997, p.177-199.

HIJWEGWN,T.; VERHAAR,M.A.; ZADOKS,J.C. Resistance to Sphaerotheca pannosa in roses induced by 2,6-dichloroisonicotinic acid. Plant Pathology, v.45, p.631-635, 1996.

KIMATI,H.; GIMENEZ-FERNANDES,N.; SOAVE,J.; KUROZAWA,C.; BRIGNANI NETO,F.; BETTIOL,W. Guia de Fungicidas Agrícolas Recomendações por Cultura, v.1, $2^{\underline{a}}$ ed. Jaboticabal: Grupo Paulista de Fitopatologia, 225p. 1997.

KUC,J. Systemic induced resistance. In: WALTERS,D.R.; SCHOLES,J.D.; BRYSON,R.J.; PAUL,N.D.; McROBERTS,N. (Ed.). Aspects of Applied Biology 42: Physiological Responses of Plants to Pathogens. Dundee: Association of Applied Biologists, 1995. p.235-242.

LO,L.C.; WEIERGANG,I.; BONHAM,C.; HIPSKIND,J.; WOOD,K.; NICHOLSON,R.L. Phytoalexin accumulation in sorghum: identification of a methyl ether of luteolinidin. Physiological and Molecular Plant Pathology, v.49, p.21-31, 1996.

LYON,G.D.; REGLINSKI,T.; NEWTON,A.C. Novel disease control compounds: the potential to "immunize" plants against infection. Plant Pathology, v.44, p.407-427, 1995. 
MERCURE,E.W.; LEITE,B.; NICHOLSON,R.L. Adhesion of ungerminated conidia of Colletotrichum graminicola to artificial hydrophobic surfaces. Physiological and Molecular Plant Pathology, v.45, p.421-440, 1994.

MING,L.C. Coleta de plantas medicinais. In: DI STASI,L.C. (Ed.). Plantas Medicinais: Arte e Ciência - Um Guia de Estudos Multidisciplinar. São Paulo: Ed. Universidade Paulista. 1996. p.69-86.

NICHOLSON,R.L.; KOLLIPARA,S.S.; VINCENT,J.R.; LYONS,P.C.; CADENA-GOMEZ,G. Phytoalexin synthesis by the sorghum mesocotyl in response to infection by pathogenic and nonpathogenic fungi. Proceedings of the National Academy Science, USA, v.84, p.55205524, 1987.

PASCHOLATI,S.F.; LEITE,B. Hospedeiro: mecanismos de resistência. In: BERGAMIN FILHO,A.; KIMATI,H.; AMORIM,L. (Ed.). Manual de Fitopatologia - Princípios e Conceitos. São Paulo: Ed. Agronômica Ceres, 1995. v.1. cap. 22, p.417-454.

PURKAYASTHA,R.P. Progress in phytoalexin research during the past 50 years. In: DANIEL,M.; PURKAYASTHA,R.P. (Ed.). Handbook of Phytoalexin Metabolism and Action. New York: Marcel Dekker, 1995, p.1-39.

SCHWAN-ESTRADA, K.R.F.; J.R.; CRUZ, M.E.S.; PASCHOLATI, S.F. Efeito do extrato bruto de plantas medicinais na indução de fitoalexinas em soja e sorgo. Fitopatologia Brasileira , v.22 (Suplem.), p. 346.

SILVA,I.; FRANCO,S.L.; MOLINARI,S.L.; CONEGERO,C.I.; MIRANDA NETO,M.H.; CARDOSO,M.L.C.; SANTIANA,D.M.G.; IWANKO,N.S. Noções Sobre o Organismo Humano e Utilização de Plantas Medicinais. Cascavel: Assoeste. 1995. 203p.

SMITH,C.J. Accumulation of phytoalexins: defense mechanisms and stimulus response system. The New Phytologist, v.132, p.1-45, 1996.

STANGARLIN,J.R.; PASCHOLATI,S.F. Proteção de plântulas de milho pipoca contra Exserohilum turcicum pelo uso de Saccharomyces cerevisiae. Summa Phytopathologica, v.20, p.16-21, 1994.

STANGARLIN, J.R.; SCHWAN-ESTRADA，K.R.F.; PASCHOLATI, S.F.; CRUZ. Efeito de frações fungitóxicas de extrato bruto de plantas medicinais no crescimento de Colletotrichum graminicola. . Fitopatologia Brasileira , v.22 (Suplem.), p. 346.

WULFF,N.A.; PASCHOLATI,S.F. Preparações de Saccharomyces cerevisiae elicitoras de fitoalexinas em mesocótilos de sorgo. Scientia Agricola, v.55, n.1, p.138-143, 1998.

YAMAOKA,N.; LYONS,P.C.; HIPSKIND,J.; NICHOLSON,R.L. Elicitor of sorghum phytoalexin synthesis from Colletotrichum graminicola. Physiological and Molecular Plant Pathology, v.37, p.255-270, 1990. 
ZADOKS,J.C. Modern plant protection. Developments and perspectives. In: ZAMBOLIM,L.; VALE, F.X.R. (Ed.). Palestras do XXX Congresso Brasileiro de Fitopatologia. Fitopatologia Brasileira, p.16-26, 1997. ZADOKS,J.C. The costs of change in plant protection. Journal of Plant Protection, v.9, p.151-159, 1992.

\section{ANEXOS}

Tabela 1 - Produção de fitoalexinas deoxiantocianidinas em mesocótilos de sorgo e gliceolina em cotilédones de soja após o tratamento com extrato bruto de plantas medicinais.

\begin{tabular}{|c|c|c|}
\hline 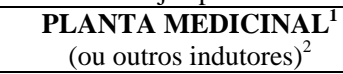 & $\begin{array}{c}\text { DEOXIANTOCIANIDINA } \\
\left.\text { (ABS }_{480} \text { /g.p.f. }\right)^{3}\end{array}$ & $\begin{array}{l}\text { GLICEOLINA } \\
\left(\mathrm{ABS}_{285} / \text { g.p.f. }\right)^{3}\end{array}$ \\
\hline Orégano & $0,97 \pm 0,15$ & $0,31 \pm 0,01$ \\
\hline Cardo santo & $0,72 \pm 0,26$ & $0,40 \pm 0,01$ \\
\hline Hortelã & $0,33 \pm 0,03$ & $0,26 \pm 0,01$ \\
\hline Alecrim & $0,54 \pm 0,02$ & $0,24 \pm 0,01$ \\
\hline Mentrasto & $0,61 \pm 0,04$ & $0,30 \pm 0,02$ \\
\hline Babosa & $1,57 \pm 0,55$ & $0,36 \pm 0,01$ \\
\hline Manjerona & $1,56 \pm 0,62$ & $0,36 \pm 0,01$ \\
\hline Erva cidreira & $2,60 \pm 0,02$ & $0,33 \pm 0,01$ \\
\hline Cânfora & $0,76 \pm 0,05$ & $0,50 \pm 0,01$ \\
\hline Pitanga & $0,37 \pm 0,05$ & $0,54 \pm 0,01$ \\
\hline Goiabeira vermelha & $0,54 \pm 0,03$ & $0,29 \pm 0,01$ \\
\hline Romã & $3,50 \pm 0,01$ & $0,43 \pm 0,01$ \\
\hline Alfavaca & $0,32 \pm 0,01$ & $0,29 \pm 0,01$ \\
\hline Mil folhas & $0,36 \pm 0,02$ & $0,28 \pm 0,01$ \\
\hline Poejo & $0,27 \pm 0,02$ & $0,49 \pm 0,01$ \\
\hline Luz ultravioleta & $0,23 \pm 0,01$ & $0,46 \pm 0,01$ \\
\hline Saccharomyces cerevisiae & $0,91 \pm 0,19$ & $0,55 \pm 0,01$ \\
\hline Colletotrichum graminicola & $15,67 \pm 0,91$ & $1,04 \pm 0,01$ \\
\hline Controle $\left(\mathrm{H}_{2} \mathrm{O}\right)$ & $0,21 \pm 0,01$ & $0,31 \pm 0,01$ \\
\hline
\end{tabular}

${ }^{\mathrm{I}}$ Extrato bruto de plantas medicinais em concentração de $20 \%$ (peso/volume);

${ }^{2}$ Outros indutores: luz ultravioleta (agente físico); $S$. cerevisiae e $C$. graminicola (agentes microbianos);

${ }^{3}$ Valor de absorbância (480 $\mathrm{nm}$ ou $285 \mathrm{~nm}$ para deoxiantocianidina e gliceolina, respectivamente) por grama de peso fresco (g.p.f.) \pm erro padrão da média. 
Tabela 2 - Efeito in vitro do extrato bruto aquoso da planta medicinal Eucalyptus citriodora sobre a germinação de esporos e formação de apressórios do fungo fitopatogênico Colletotrichum graminicola.

\begin{tabular}{|c|c|c|}
\hline \multirow{2}{*}{$\begin{array}{l}\text { CONCENTRAÇÃO DO } \\
\text { EXTRATO BRUTO }(\%)^{1}\end{array}$} & \multicolumn{2}{|c|}{ PORCENTAGEM DE } \\
\hline & GERMINAÇÃ̃O $^{2,4}$ & APRESSÓRIOS ${ }^{3,4}$ \\
\hline 1 & $29,5 \pm 3,8$ & $78 \pm 4$ \\
\hline 5 & $41,5 \pm 3,2$ & $94 \pm 5$ \\
\hline 10 & $44,5 \pm 5,3$ & $86 \pm 6$ \\
\hline 20 & $59,5 \pm 3,8$ & $71 \pm 2$ \\
\hline 50 & $57,5 \pm 8,1$ & $66 \pm 3$ \\
\hline Controle $\left(\mathrm{H}_{2} \mathrm{O}\right)$ & $24,0 \pm 2,8$ & $100 \pm 0$ \\
\hline
\end{tabular}

${ }^{1}$ Porcentagem: peso fresco de folhas por volume de solução;

${ }^{2}$ Foram considerados germinados os esporos que apresentavam comprimento de seu tubo germinativo pelo menos igual ao menor diâmetro do esporo;

${ }^{3}$ Porcentagem de apressórios calculada em relação ao número de esporos germinados;

${ }^{4}$ Valores representam a média de 100 contagens \pm erro padrão da média.

Tabela 3 - Efeito in vitro do óleo essencial das plantas medicinais Ocimum basilicum, Ruta graveolens e Baccharis trimera sobre o crescimento micelial dos fungos fitopatogênicos Rhizoctonia solani, Sclerotium rolfsii, Alternaria alternata e Phytophthora sp.

\begin{tabular}{l|c|c|c|c|c}
\hline $\begin{array}{c}\text { PLANTA } \\
\text { MEDICINAL }\end{array}$ & $\begin{array}{c}\text { Alíquota } \\
(\mu \mathrm{l})\end{array}$ & \multicolumn{4}{|c}{ INIBIÇÃO DO CRESCIMENTO MICELIAL $(\%)^{\mathbf{1}}$} \\
\cline { 3 - 6 } & & $\boldsymbol{R}$. solani & S. rolfsii & A. alternata & $\begin{array}{c}\text { Phytophthora } \\
\text { sp. }\end{array}$ \\
\hline B. trimera & 20 & 75 & 77 & 76 & 76 \\
\hline & 40 & 80 & 85 & 85 & 85 \\
\hline & 100 & 82 & 95 & 95 & 95 \\
\hline R. graveolens & 20 & 100 & 100 & 45 & 100 \\
\hline & 40 & 100 & 100 & 74 & 100 \\
\hline
\end{tabular}

${ }^{1}$ Avaliação realizada 3 dias após o início do experimento para $R$. solani e $S$. rolfsii, 4 dias após para Phytophthora sp. e 5 dias após para A. alternata. O valor de inibição é em relação ao diâmetro da colônia fúngica obtida no tratamento controle. 